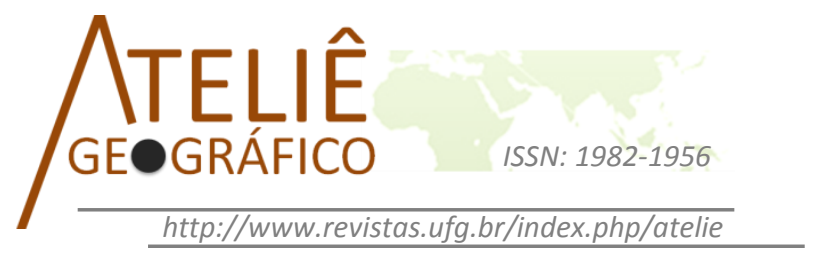

\title{
A luta pela terra, a luta pela vida: a interveniência das Políticas Públicas no Território do Povo Indígena Tapuia em Goiás
}

The struggle for land, the struggle for life: the intervention of public policies in the Territory of the Tapuia Indigneous People in Goiás

La dispute pour la terre, la dispute pour la vie: l'influence des politiques publiques au territoire du peuple Indigènes Tapuia en Goiás

Lorranne Gomes da Silva

Universidade Estadual de Goiás

lorrannegomes@gmail.com

\section{Resumo}

O Povo Indígena Tapuia, que se localiza na aldeia Carretão, nos municípios de Rubiataba e Nova América no Estado de Goiás, a partir de sua história, revela como os Povos Indígenas foram e são tratados no Brasil. Suas trajetórias apresentam a luta pela terra e por uma identidade étnica violada pela interferência de interesses econômicos dos fazendeiros da região e por um período de aldeamento, que provocou uma reconfiguração de suas práticas culturais. Os índios que não fugiram do aldeamento casaram-se entre si ou com negros escravos e brancos. Essa miscigenação fez com que o modo de vida indígena tornasse semelhante com o modo de vida camponês. Este povo passou por um período de "abandono" pelo Estado e pela própria Fundação Nacional do Índio (FUNAI), que pouco propiciou ações para melhoria da realidade desse povo. As escassas políticas públicas ao mesmo tempo em que se voltaram para melhoria da saúde, da alimentação e de projetos coletivos, não consideraram a necessidade de maiores quantidades de terras, nas quais, assegurariam uma reserva adequada para a sobrevivência dos índios e suas práticas culturais. Esse artigo é uma janela que se abre para mostrar mais um caso de desrespeito e violação dos direitos indígenas. Como metodologias para construção desse texto foram utilizadas 
pesquisas bibliográficas, trabalhos de campo $^{1}$, rodas de conversas e entrevistas semi-estruturadas.

Palavras-chave: Povo Tapuia. Território. Trajetórias. Identidade. História. Direitos.

\begin{abstract}
The history of struggles for a group survival of the Tapuia indigenous people, who live in the Carretão village in the municipalities of Rubiataba and Nova America, state of Goias reveal how the indigenous minorities are treated in Brazil. Their life journeys show a strife for land ownership and ethnic identity which were violated due to the economic interests of farmers and the formation of a self-enclave in the region, which led to new meanings and a kind of redefinition on their cultural practices. The Indigenous people that did not leave the village, married to one another or to black slaves and/or to white people. This miscegenation had negative impacts on the indigenous way of life and it's became very similar to the peasant one. These people went through a period of "abandonment", by the National Indian Foundation (FUNAI), and by the State, which did not take actions to improve their reality. The sparse public policies have a focus in health, food security and collective projects, however this policies did not consider the indigenous need for greater amounts of land which would ensure their livelihood and cultural practices. This article is a window that opens to show another example of disregard and violation of indigenous rights. The methodology used for this article was literature review, fieldwork, conversations and semi-structured interviews.
\end{abstract}

Keywords: Tapuia Indigenous People. Territory. Identity. History. Legal Rights.

\begin{abstract}
Résumé
Le peuple indigène Tapuia, situé dans la communauté Carretão aux municipes de Rubiataba et Nova América, dans leur histoire, révéle comme les peuples indigènes ont été traités au Brésil. Leurs trajectoires présentent la dispute pour la terre et pour une identité éthnique violée par l'interférance des interêts économiques des fermiers de la région et par un période de la constitution de la communauté, qui a provoqué une ressignification des leurs pratiques culturelles. Les indigènes n'ont pas pris une fuite de la communauté, ils ont marrié parmi eux ou avec des noirs fait esclaves ou des blancs. Cette mélange ont a transformé le mode de vie indigène en mode de vie du paysan. Ce peuple a passé par une période d' «abandon» des autorités indigènistes et par d'État y de la propia Fundación Nacional del Indio (FUNAI) qui n'ont pas eu des actions pour améliorer la réalité de ce peuple. Peu de politiques publiques ont amélioré la santé, l'alimentation et les projects colletifs, mais elles ont pas consideré la necessité des terres pour une réserve adéquat aux leurs pratiques culturelles. Cet article prétend montrer l'insolence et la violation des droits indigènes. Comme methodologie pour construire le texte on a fait utilisées des recherches bibliographiques, des travaux à la campagne, des roues de bavardage et des interviews.
\end{abstract}

Palavras-chave: Peuple Tapuia. Territoire. Trajectoires. Identité. Histoire. Droits.

\footnotetext{
${ }^{1}$ Alguns trabalhos de campo foram financiados pelo projeto BIOTEC (Biotecnologias e Biodiversidade Gestão Participativa no Cerrado Brasileiro) - Realizado entre os anos de 2010 e 2012 pela Universidade Federal de Goiás, desenvolvido no Instituto de Estudos Sócio-ambientais (IESA) em parceria com o Institut de Recherche pour le Develóppement (IRD) da França.
} 


\section{Considerações Iniciais}

Uma interrogação panorâmica tem estruturado as investigações que o grupo de Pesquisa - Povos Indígenas do Cerrado - tem feito: o que é ser índio no Cerrado Goiano? Essa indagação conduz a reflexão: como os povos indígenas do Cerrado goiano, de acordo com as vicissitudes econômicas e políticas das últimas décadas, têm construído a sua vivência nesse território atravessado de conflitos e disputas.

A consideração de que o estudo dos povos indígenas do Cerrado goiano demanda por reconhecer a especificidade histórica de cada um desses povos e a necessidade de ajustar as dimensões históricas às dimensões espaciais, por certo nos indicam que esses povos possuem desafios semelhantes. Deve-se avaliar que todos estão imersos na realidade do Cerrado. Mas há também dados e faces específicas, pois cada povo possui características que são inerentes à sua história e ao seu lugar na rede diferencial das regiões goianas.

As determinações históricas que podem gerar uma identificação da gênese da formação dos povos indígenas no Estado de Goiás e sobre os aldeamentos, são baseadas, de acordo com Trindade (2009, p.22): “em relatórios de viajantes, depoimentos dos próprios índios e documentos oficiais do governo". Percebe-se que a história indígena de Goiás é desse modo, aberta a novas pesquisas e a outros investimentos teóricos e metodológicos.

No século XVIII os aldeamentos em Goiás começam seus declínios ao serem marcados por uma considerável redução populacional indígena. Os povos indígenas foram "abandonados" e tiveram que lutar pela sobrevivência por meio de estratégias próprias de sua cultura, de sua força e de sua renitência e amor pela vida.

Com a decadência da mineração, no século XIX, a economia goiana entrou em uma grande crise, o que veio a afetar a existência dos povos indígenas de Goiás. A emergência de uma economia ligada à agricultura gerou um crescente interesse por terras destinadas às lavouras e à pecuária. Esse processo abriu campo para diversos conflitos que não apenas aniquilaram levas enormes da população indígena, mas deixaram marcas traumáticas que, ainda hoje, no século XX, intervém na maneira com que alguns povos olham o futuro e temem o presente.

Geralmente perseguidos e mortos, muitos chacinados em grandes devido o interesse por suas terras, riquezas e águas, Goiás adentrou no século XX sem nenhuma resolução dessa problemática. E ela foi-se agravando principalmente no antigo norte goiano, hoje Estado do Tocantins. E também com o processo econômico que, aos poucos, ia dando à terra um valor de troca. 
Em 1940 iniciou-se a política do Governo Getúlio Vargas chamada "Marcha para o Oeste". Com o objetivo formal de preencher os vazios demográficos, principalmente no centro-sul do país, da qual Goiânia foi, na década anterior, era o grande exemplo de êxito, a valorização das terras e a institucionalização da emergente modernização, juntamente com a ideologia desenvolvimentista que balizava as plataformas da construção do imaginário da nação, os povos indígenas assim como os camponeses eram tidos como entraves históricos, peças negativas para o rompante do progresso.

Tanto no plano objetivo como no ideológico, esse processo em Goiás foi bastante intenso. De acordo com Chaveiro (2001, p.133) iniciava-se: o "marco divisório de um padrão territorial que estava sendo inaugurado no país, de que Goiás, necessariamente, receberia os impactos e participaria de maneira decisória".

Na década de 1950, a rede ferroviária e a construção das rodovias proporcionaram uma nova reorganização espacial, o que possibilitou a formação de um complexo urbano/rural, principalmente no sul e sudoeste de Goiás. A nova colonização de Goiás, agora cunhada com as vias, ia exercendo uma pressão nos territórios indígenas.

Conforme Estevam (1998, p. 143): "A partir de 1950, embora timidamente, iniciou-se um processo de mecanização na agricultura goiana". Essa modernização é fruto do processo de modernização urbana, que segundo Estevam (1998, p. 80) "não foi propriamente a agricultura que se industrializou, mas a indústria que industrializou a agricultura".

A transnacionalização de sistemas ampliados de consumo e de capitais, estruturados em um crescente processo de urbanização da sociedade brasileira, a partir da década de 1960, é responsável pelo modelo de desenvolvimento que orientou a ocupação e a organização da economia goiana e da qual também Brasília passou a ser ícone. A inserção de Goiás na economia nacional e a internalização do modelo econômico do mundo rico contrastava, cada vez mais, com a cultura e o modo de vida indígenas.

No final da década de 1970 e início da década de 1980, como resultado da política de modernização da agropecuária e do território, fez com que a economia goiana passasse por transformações significativas. $\mathrm{O}$ objetivo central era estreitar as relações entre o setor agrícola e o setor urbanoindustrial. Estevam (1998, p.172) afirma que:

O financiamento rural foi poderoso instrumento de 'modernização' da agricultura ao possibilitar incorporação de maquinário e insumos ao processo produtivo. As modificações 
técnicas na exploração agropecuária em Goiás, em função do crédito rural foram intensas na década de 1970.

O Estado e os grandes produtores, num pacto de interesse de classes, protagonizaram a integração de Goiás no país desintegrando as regiões e valorizando os lugares em função de sua dinâmica econômica.

Vários setores se incorporaram nesse processo e sofreram mudanças em seus conteúdos como as relações de trabalho, o padrão tecnológico, a distribuição espacial da produção, as relações intersetoriais. Essas grandes modificações e transformações aconteceram, principalmente, pela via capitalista e por todo tipo de alterações culturais, econômicas e principalmente ambientais. Como afirma Mendonça: “... a partir desse momento pode-se dizer que a matriz espacial de Goiás é a modernização" (2004).

Assim, o Cerrado foi incorporado na modernização agrícola em 1970. Grande parte do Cerrado (biodiversidade e cultura) foi "invadido" pela reprodução ampliada do capital moderno. Ressignificado pela batuta econômica, fragmentado em suas regiões e contaminado pelos novos vetores da produção baseada em aportes mecânicos e químicos, a pressão sobre os povos indígenas passou a ser cada vez maior.

O bioma passa ser um atrativo para a produção de soja e cana, uma vez que se amplia a demanda do produto nos mercados internacionais. Diante desse cenário de modernização, o fator posição foi importante. Nota-se, por exemplo, que os lugares em que o processo de modernização foi mais intenso diretamente não sobraram nenhum povo indígena.

A ressignificação do Cerrado goiano tornou-se esse território como alvo de disputas de várias ordens. Portanto, o que o valora, também, o destrói drasticamente já que essa valorização está voltada ao lucro e a produtividade que arrasa e extermina constantemente as áreas de Cerrado. Para Chaveiro (2008, p. 89):

Em síntese, a perspectiva economicista valoriza o cerrado apenas pela patente econômica fundada no critério de rentabilidade para qual o destrói enquanto vida. Por isso, a visão economicista é mórbida, fragmentadora, utilitarista. Impõe a vida para a economia. Não uma economia para a vida.

Ao considerar a realidade do Cerrado goiano, a preocupação que se encontra nas entrelinhas deste artigo é a reflexão sobre o que está acontecendo com os povos indígenas em Goiás. Como eles resistem diante da vasta incorporação do capital em seu solo, ou como essas mudanças externas são 
incorporadas internamente no modo de viver dos povos indígenas que aqui habitam?

Pela relevância dessas e outras questões, é possível fazer uma reflexão sobre o Povo Indígena Tapuia do Cerrado goiano, sobretudo compreender como esse povo resistiu e resiste às lutas e disputas pela terra; como as Políticas Públicas são efetivadas nesse Território Indígena diante do cenário socioeconômico atual. Vale dirigir a atenção também para averiguar os agentes que estão em conflitos, incluindo signatários da causa indígena e setores que ainda o vêem como entrave do avanço econômico.

\section{O Povo Tapuia}

A primeira classificação dos índios brasileiros depois da colonização foi feita entre os habitantes do litoral vindos do Sul em migração, os Tupis, tidos como mansos, dóceis e de língua boa e os índios do interior, do sertão, os Tapuias, índios bravos e de língua travada.

Tapuia quer dizer na língua Tupi "bárbaro" ou "inimigo". Os Tupis chamavam aqueles que viviam na Tapuiretama (no interior) de Tapuios ou Bárbaros. Tal nome era ainda a denominação dada pelos portugueses a indígenas dos grupos que não falavam línguas do tronco tupi e que habitavam no interior do Brasil. Seus grupos viviam distantes e independentes uns dos outros. Guerreavam entre si, ou contra os Tupis.

Essa classificação foi a que perdurou por mais de quatro séculos. Cronistas, como governadores, viajantes, missionários, fazendeiros e outros, perpetuaram essa classificação em seus registros e, só no alvorecer do século $\mathrm{XX}$, os pesquisadores evidenciaram que os tapuias, na verdade, compreendiam outros grupos étnicos distintos, como os Cariris, os Caraíbas e, sobretudo os Gês.

De acordo com dados históricos, os Tapuia eram nômades (não construíam casas) e paravam onde havia abundância de alimentos. Alimentavam-se com mel de abelhas, maribondos, cobras e lagartos, plantavam mandioca e gostavam de viver ao ar livre. Adoravam as forças da natureza como o trovão, a lua, o sol, e acreditavam em certos animais, como serpentes, aves e alguns mamíferos, como morcegos. Praticavam sacrifícios de animais, até humanos e também tinham como Deus principal a Constelação da Ursa Maior e não faziam nada sem antes consultar os sábios e anciões da aldeia. As suas armas eram as flechas, as pranchetas, arcos e dardos, que usavam com grande habilidade. Também usavam as clavas e machados de mão. 
Infelizmente, as políticas de aldeamento que ocorreu na colonização no Brasil foram circunstanciais para redefinir e reconfigurar vários elementos das culturas indígenas, como no caso dos Tapuia. As perseguições e massacres que se sucederam para a apropriação dos territórios marcaram o fim de vários povos. As reestruturações e resistências desses povos são marcos de lutas e fugas para sobreviver.

\section{O Povo Indígena Tapuia do Cerrado goiano}

As políticas indigenistas em Goiás, além da utilização da prática de aldear para civilizar, catequizar ${ }^{2}$ e pacificar os índios, também consideravam o mecanismo do aldeamento ${ }^{3}$ uma estratégia eficaz para desocupar as terras habitadas por povos indígenas.

Percebe-se, por isso, que a terra como um componente orgânico da cultura indígena esteve no âmago da disputa por setores sociais hegemônicos, desde a gênese com a Bandeira do Anhanguera. Essas terras, posteriormente, serviriam para atividades ligadas à mineração e atividades agropastoris.

Em consonância com as informações que se tem sobre o povo Tapuia e em relatórios do Barão de Mossâmedes ${ }^{4}$, sua origem étnica está centrada nos primeiros habitantes do aldeamento Carretão ou Pedro II, construído na região central da Província de Goiás, em 1788, para abrigar os índios Xavantes no segundo período da política de construção de aldeamentos oficiais, quando a agropecuária já se implantava em Goiás, substituindo o decadente ciclo da mineração de ouro.

Priorizou-se, então, a criação e/ou fortalecimento de núcleos populacionais, já que muitos haviam sido desativados. Para isso, tornava-se necessária a captura dos índios hostis, que "impediam", com seus ataques, o crescimento dos povoados. O objetivo era transformar esses indígenas em "civilizados", não só para que fossem a base de novos povoamentos, mas também para transformá-los em mão-de-obra para a lavoura.

A população do Carretão nome da Terra Indígena Tapuia, como atestam depoimentos de diferentes autores, sofreu sérios reveses, como fome,

\footnotetext{
${ }^{2}$ A igreja católica liderou por muitos anos esse processo de catequização dos povos indígenas, com o objetivo de fazer com que os índios se convertessem ao cristianismo, religião dominante.

${ }^{3}$ A prática de aldear, concentrar ou reunir diferentes grupos indígenas em um mesmo local (aldeamento) foi iniciada, no Brasil, em meados do século XVI e estendeu-se até o XIX. O aldeamento tinha como objetivos a cristianização e a civilização dos indígenas. Os métodos utilizados adaptavam-se às condições locais e políticas adotadas em cada região e época, em conformidade com as leis e códigos de Portugal.

${ }^{4}$ Capitão - General da capitania de Goiás.
} 
doença, tratamento ofensivo, e até perseguição por parte dos empregados do aldeamento.

Darcy Ribeiro (1979) comenta que a população do Carretão teve que conviver intimamente com guarnições militares e experimentar a vida civilizada. Não deve ter apreciado a experiência, porque, logo depois, começou a escapar rumo ao norte, para o antigo território tribal. Anos depois, o aldeamento estava praticamente deserto e os Akuên (Xavante) reiniciaram suas hostilidades.

Para Moura (2006) até a metade do século XIX, existem relatos de vários autores que dizem ter encontrado grupos Xavante em aldeamentos oficiais, bem como notícias de seus ataques à população goiana nas regiões de Crixás, Pilar e Tesouras, que ficam próximas da área do aldeamento Carretão.

A partir do início do século XX, voltam a circular notícias sobre os Xavante, já no estado do Mato Grosso, transmitidas por antropólogos, historiadores, sertanistas e, sobretudo, por religiosos da Missão Salesiana, que, desde 1932, iniciou tentativas de contato com esse grupo.

Os Xavante, no Mato Grosso, resistiram radicalmente ao contato com o branco, atacando membros das expedições que se organizavam para esse fim. Em 1950, os Xavante foram finalmente "pacificados". Para Darcy Ribeiro (1979, p.65), "se rendem à paz, que jamais desejaram".

O aldeamento Carretão teve vida curta. Várias são as causas apontadas para a sua decadência. Para Ravagnani (p. 51, 1991):

\begin{abstract}
A decadência econômica arrastou consigo toda a política indígena desenvolvida pelos últimos governadores. Este fato mudou radicalmente a orientação seguida pelos governadores, os quais falavam em abolir tão caros e majestosos empreendimentos.
\end{abstract}

Até as duas primeiras décadas do século $\mathrm{XX}$, viviam no local do antigo aldeamento Carretão alguns remanescentes indígenas, conhecidos pela população regional, como "tapuios". Em 1936, a área onde estava instalada o aldeamento Carretão foi ocupada por um fazendeiro da região de Goiás.

E, em 1944, a área foi requerida ao estado de Goiás, como terra devoluta, por um fazendeiro. $\mathrm{O}$ aldeamento foi transformado em uma fazenda, hoje propriedade de um fazendeiro.

\title{
O Território Tapuia
}


Atualmente os Tapuios moram no perímetro do antigo território Carretão, mas fora da localização original das construções na Terra Indígena Carretão, situada entre a Serra Dourada e o Rio São Patrício (ou Carretão) nos municípios de Rubiataba e Nova América, como mostra a figura 01:

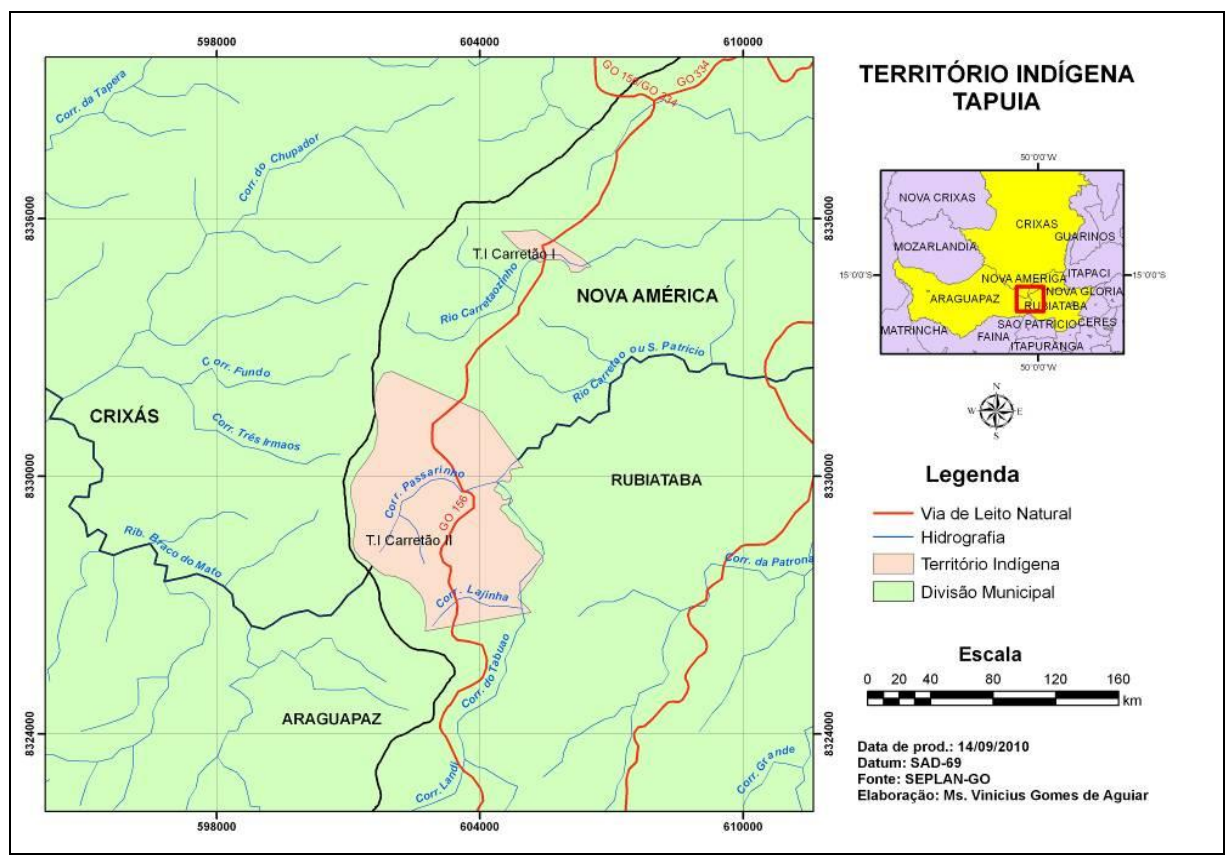

Figura 01: Localização do Território Indígena Tapuia-GO

A Terra Indígena é cortada por vários córregos o que torna a Reserva abundante em água. A região é serrana, e as espécies de Cerrado, especialmente o Cerrado stricto senso e o Cerradão é a vegetação natural. A terra possui muitos aclives e declives. Nos declives é desenvolvida a pecuária extensiva e rudimentar; nos terrenos mais planos a agricultura simples. De acordo com Trindade, (2009, p.45): "A área indígena é cortada por uma estrada, conhecida entre os Tapuia por "estrada carreteira", devido ao grande fluxo de transportes de gado, atualmente feito em carretas".

A Terra Indígena é composta por duas glebas não contínuas: a Gleba 1, subdividindo-se em Gleba 1-A, localizada no município de Nova América, e a Gleba 1-B, localizada no município de Rubiataba, totalizando 1.666 hectares; 
e a Gleba 2, localizada também no município de Nova América, com uma área de 77 hectares.

As duas glebas perfazem um total de 1.743 hectares que foram demarcadas em 1984, em meio de intensos conflitos com os fazendeiros da região. A figura 02 mostra o uso da terra do território indígena:

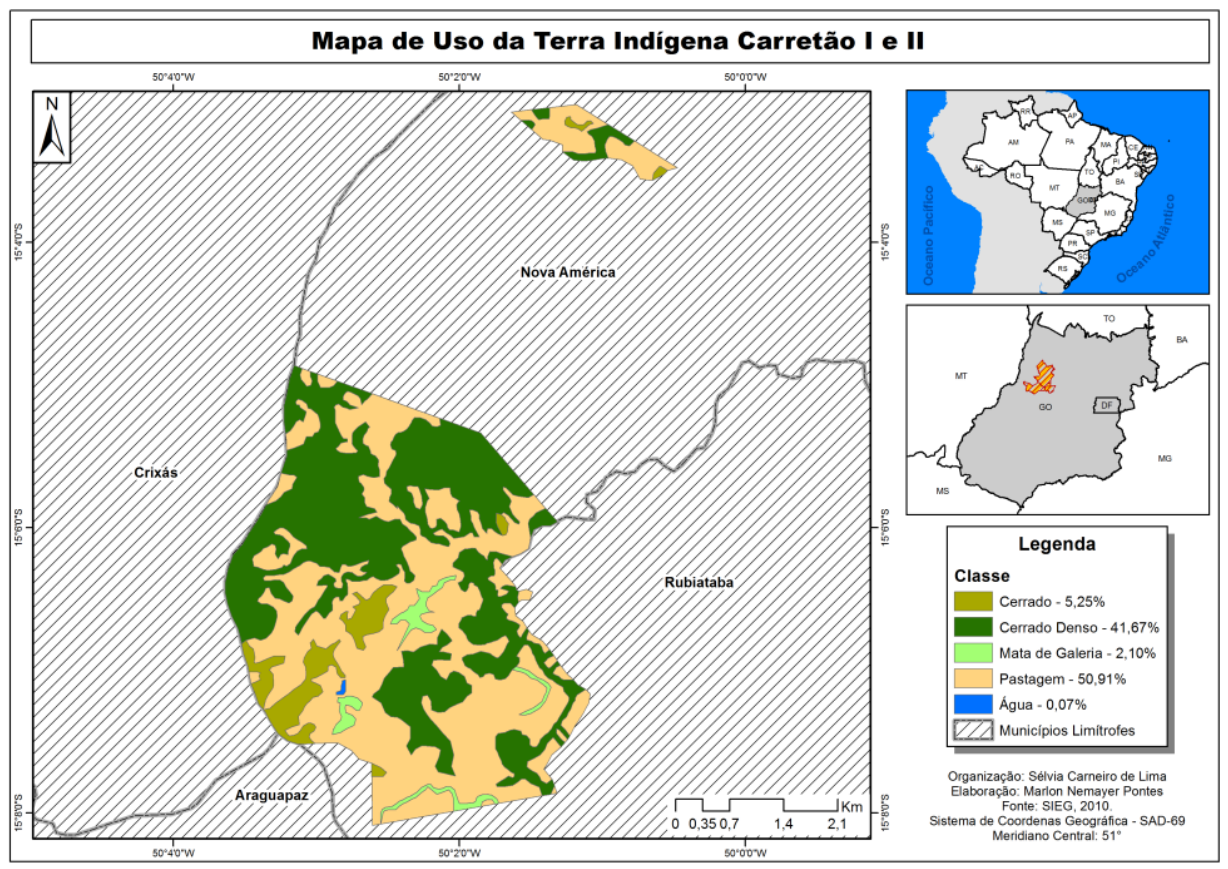

Figura 02: Uso da Terra Indígena Tapuia-GO

Em consideração ao uso da terra a divisão foi feita pelos próprios índios. Em comum acordo destinaram uma parte para uso coletivo, onde se construiu uma Lavoura Comunitária e o restante foi dividida particularmente entre as famílias da aldeia.

Nessa demarcação, a antiga sede do aldeamento Carretão, que deu origem ao povo e onde foi construído, o cemitério, ficaram fora da área delimitada. Tal fato provocou insatisfação no seio do povo Tapuia ao verem territórios sagrados e importantes de sua ancestralidade fora dos limites da Terra Indígena como mostra a figura 03: 


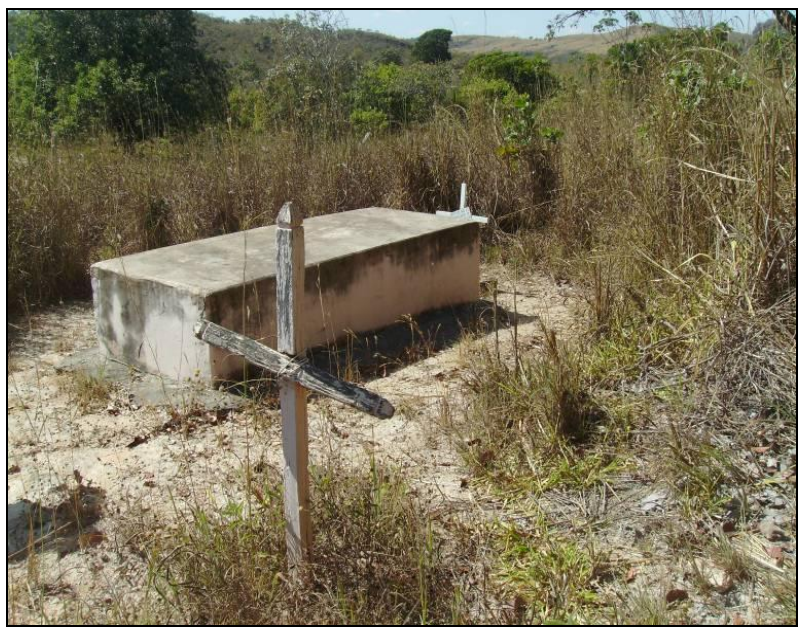

Figura 03: Cemitério Tapuia.

Fonte: fotografia da autora (2010)

Do grande aldeamento de 1800, dos 5.000 índios, hoje os Tapuia somam aproximadamente 200 pessoas $^{5}$ (FUNAI, 2010), o que representa um drástico declínio demográfico desse povo que, no passado, foi até motivo para obras literárias como o clássico: Cem noites Tapuias, dos escritores Ofélia e Narbal Fontes, enquadrado na conhecida "Série Vaga-lume" da Editora Ática de São Paulo. Silva (2000, p. 20), considera que:

A organização social e a situação histórica dos tapuios hoje é, em larga medida, resultado da história de "contatos" interétnicos promovidos pelo avanço dos regimes coloniais (português e brasileiro, principalmente) que tinham por prática os "descimentos" ou "pacificações" dos povos indígenas vistos como "obstaculizadores" à ocupação expansionista, impedindo a conquista efetiva dos territórios visados por estas verdadeiras frentes de expansão estatais.

O povo Tapuia sempre lutou por sua identidade étnica, tanto institucional-ser reconhecido pelo Estado como índio - como social - o que os fazem ser índio para a sociedade. A luta pelo reconhecimento identitário permeia a história desse povo até mesmo na etimologia do nome Tapuia, que segundo Silva (2000, p.8):

Ao considerar a etimologia do termo "tapuia" e reconhecendo que sua ocorrência particular em situações sociais em que esta palavra

\footnotetext{
${ }^{5}$ Algumas famílias vivem fora da área Terra Indígena.
} 
é utilizada acabou por convertê-la em um etnônimo temos, por um lado, que o termo "tapuio" é uma referência genérica a índios e não o nome de uma etnia, e por outro, a construção da própria autodenominação de um grupo étnico.

Conforme indica a etimologia da palavra "Tapuia", foi o olhar do Outro, especialmente de fazendeiros da cercania que, de início, interferiram na construção identitária. Mas apesar das ressignificações culturais, o modo de ser índio resistiu, porém resultou numa leve fusão ao modo de vida camponês.

A vitalidade do fato histórico promovido pelo aldeamento tal como foi narrado, é constatado quando se aproxima do território Tapuia. Num primeiro momento, a prática de conversar em círculo, os dispositivos da culinária, a paixão pelo futebol, e mesmo as atividades da pecuária e da agricultura, podem nos conduzir a pensar que se trata da simplicidade da vida do tradicional camponês goiano.

Todavia, à medida que se aproxima mais profundamente, a organização do tempo, o olhar profundo e às vezes desencantado, os traços corporais, alguns saberes vê-se que trata de povos indígenas logrados pelo aldeamento. Além de ter provocado uma resignificação da cultura Tapuia, a política de aldeamento deixou marcas indeléveis, como pode-se perceber na fala de um dos indígenas:

"Não temos uma língua própria já que temos origem de um aldeamente entre quatro etnias: os Xavante, os Xerente, os Karajá e os Kaiapó, além de negros vindos de Pilar de Goiás - mas tentamos realizar alguns rituais $e$ costumes de nosso povo - há um ressurgimento da pintura e de algumas danças".

Essas marcas também são resultados dos conflitos pela terra com os fazendeiros da região que, como foi explicado anteriormente, "desvalorizavam" a cultura indígena e até negavam a presença dos povos indígenas para facilitar a apropriação da terra. De acordo com Trindade (2009, p. 41):

Para atingir o objetivo proposto, os fazendeiros procuravam, de antemão, descaracterizar fisicamente os Tapuio como índios, ignorando as contribuições indígenas em sua formação e ligando sua imagem unicamente à dos negros, seus descendentes.

Atualmente, a língua do povo Tapuia é o português. Compassada e simpática, cheia de atrativos e de alta capacidade de receber o Outro, inclinada às tramas do lugar mais que aos desvelos universais da cultura, o modo de falar 
Tapuia foi um argumento utilizado pelos fazendeiros para também negar a identidade indígena.

Tal fato nos remete rememorar como a história é atravessada por contradições. Durante o período colonial, a Língua Portuguesa foi imposta aos indígenas como única aceitável, e atualmente no caso dos Tapuias "índio para ser índio não pode falar português". Observa-se que o aliciamento dos bens indígenas inclui a sua cultura e o sentido histórico dela.

As casas dos Tapuias são construídas de maneira bem semelhante de um camponês. São distantes uma das outras. Entre elas são desenvolvidas pequenas atividades agrícolas. Há um grande uso dos quintais com hortas e geralmente são as mulheres que plantam e cuidam.

É válido analisar a chegada da tecnologia nos territórios indígenas e a sua relação com o seu modo de vida. Tal acontecimento fica evidente nos depoimentos de alguns sujeitos indígenas:

"Aqui na aldeia temos parabólicas e telefone público - até o final do ano está pronta uma antena para celulares - as tecnologias vão aos poucos chegando na aldeia - Temos que andar junto com o mundo"!

"No mês de agosto e setembro pescamos muito - no Rio cabeceira do Tesoura no braço do campo e no braço do mato a $25 \mathrm{~km}$ da aldeia.Eu gosto muito de pescar, esqueço de tudo e só escuto o barulho do rio".

"Eu adoro jogar futebol, nosso time é muito bom temos até torcida organizada pelas meninas. Aqui todos os jovens jogam futebol, as meninas também têm um time. Todos os finais de semana tem futebol na aldeia".

"Fazemos alguns rituais sim, só com os mais velhos. Encontramos com nossos antepassados".

Essas falas demonstram as ressignificações da cultura deste povo com incorporações da vida indígena e não-índigena. Entretanto, se antes, por medo, os Tapuia escondiam sua identidade, hoje apresentam confiança em identificarse como índio e contam sua história com alegria de quem superou inúmeros obstáculos.

E sabem que no atual período, a consistência identitária lhes pode render mais força para compor, juntamente com gente das universidades, setores do Movimento social e de organização indígenas mais conquistas. 
Portanto, com as transformações advindas pelo tempo alguns questionamentos passam a existir: como a juventude Tapuia, criada num território urbanizado como é o caso de Goiás, desenvolve sua identidade neste século XXI? Como ocorre o relacionamento desses jovens com os mais velhos, com a família, e as tradições? Como é a relação com a terra?

Uma corrente museificadora especialmente filiada aos interesses de fazendeiros para retirar a legitimidade identitária dos povos indígenas, geralmente insiste em criar um imaginário que "os jovens tapuia bebem muito, jogam futebol, estudam, vêem televisão etc". Como se tivessem condenados a abandonar o mundo real e as conquistas sociais coletivas como a Educação, pela via desse imaginário cabe aos povos indígenas, especialmente os jovens, ficarem à margem dessas conquistas. Para Silva (2000, p.04):

\begin{abstract}
Devemos ter sempre em mente que se dizer índio implica suportar todo o peso de uma identidade institucionalizada, imposta sobre certos grupos socioculturalmente diferenciados, partindo de atributos "escolhidos" para operacionalizar uma administração, ao mesmo tempo que, o ser indígena se refere a representações que povoam o senso comum.
\end{abstract}

Estes pensamentos e formas de qualificar o povo indígena fazem parte da disputa territorial. Os que se mantêm mais isolados, como é o caso dos Avá-Canoeiro no norte de Goiás, são tratados de não trabalharem, irem contra o tempo, serem atrasos por serem totalmente amparados pela FUNAI.

Os que inserem no mundo mesmo mantendo laços fortes de sua cultura são nomeados de não-indígenas. Deve-se observar que em qualquer sociedade, mas especialmente nas contemporâneas, as significações e os elementos que constituem uma identidade são muito complexos. Silva (2000, p. 10) afirma que:

\begin{abstract}
A situação histórica dos tapuios me faz perceber que enquanto se pensar nos índios como "outros" radicalmente diferentes desde sempre e em qualquer circunstância, não se poderá encarar suas ações e reações (rituais, políticas, etc.) como um comportamento criativo, i.e., construído em relação contrastiva com seus próprios "outros", mas apenas enquanto um comportamento imutável e etnograficamente estranho.
\end{abstract}

Apesar da existência de conflitos materiais, institucionais e objetivos bem como de níveis subjetivos como os imaginários e de imagens, os povos Tapuia resistiram - e resistem. Recebem também apoio de setores organizados de diferentes estirpes e agem diariamente constituindo com a sua vida o seu lugar no território em disputa, tal como é o Cerrado atual. 


\section{As Conquistas e as Lutas do Povo Tapuia}

Uma questão central é: como os povos indígenas podem organizar a sua inserção neste território tal como ele se caracteriza? Essa pergunta indica que há um elemento político na causa indígena que, por sua vez, diz respeito ao modo como o Estado gera sentido para o território que governa.

Daí, ser a política pública, da parte do Estado juntamente com os códigos legais, o que assinala o comprometimento ou não do Estado com os povos indígenas. E o nível de ação dos povos indígenas juntamente com os seus aliados, o termo de resistência que opera a ação de seu poder para enfrentar ou ceder aos ditames do Estado.

Com a proteção constitucional das Terras Indígenas, garantida desde a Constituição Federal de 1934 no seu artigo 129, que legitima o direito à posse das terras por eles ocupadas permanentemente, e veda a alienação, até hoje, no século XXI, a conquista legal pelo território indígena ainda é uma questão polêmica, desrespeitada e mal resolvida no Brasil.

Dessa forma, é comum conflitos em variadas direções em que estão presentes interesses de madeireiros, mineradores, latifundiários, indústrias energéticas, empreendedores imobiliários e de turismo etc.

Os povos indígenas vivem grandes dilemas no mundo atual. Um dos principais dilemas diz respeito à garantia da demarcação de suas terras e a permanência em seus territórios, incluindo o respeito pelos seus saberes, modos de vidas, costumes, festas e tradições.

Com a expansão do capitalismo no campo, de acordo com que refletimos anteriormente, os territórios indígenas sofreram outro nível de ameaça que detonou uma nova cartografia de conflitos. Esses conflitos ocorrem mais diretamente pela disputa e posse da terra por fazendeiros, latifundiários e empreendimentos do capital. Mesmo as terras que são demarcadas e garantidas por lei são violadas pelos atores das modernas fazendas capitalistas.

Mesmo que a constituição Federal de 1988 tenha ampliado os direitos indígenas, legitimando o direito às terras e ao desenvolvimento da cultura própria de cada povo, incluindo o direito de estudar na língua materna, os conflitos não cessaram. Pelo contrário, ganharam desvelos mais complexos.

Que direitos tem os povos indígenas hoje em relação à posse de seus territórios tradicionais que estão sendo vilipendiados?

Além de viverem constantemente com os conflitos de terra, os indígenas relatam que em comparação com outros povos indígenas de Goiás, 
Karajá e Avá-Canoeiro, os Tapuia foram abandonados pelas autoridades políticas. E que mesmo após a demarcação das terras continuaram com assistência precária do órgão indigenista - FUNAI. Moura (1996, p.102), afirma que até 1979 os Tapuia desconheciam a existência da FUNAI. Vê-se que a diminuição drástica de sua população tem uma linha direta com a ação do Estado.

A perda cada vez mais significativa do território atingiu consideravelmente a vida dos Tapuia, que acabaram tendo dois olhares sobre a terra como afirma Silva (2000, p. 24):

\begin{abstract}
Por um lado, os tapuios valorizam a terra como o lugar onde nasceram seus pais e avós, onde estes cresceram e contaram suas histórias e biografias, onde se viveu, onde se morre. Tornando evidente a questão identitária vinculada à territorialidade e ao tempo vivido em um lugar. Por outro lado, se percebe uma valorização da terra como propriedade, como valor de uso e de troca, como meio exclusivo de produção econômica e exploração humana.
\end{abstract}

Uma vez que precisam sobreviver e não tinham recursos para tal, a solução mesmo foi alugar as terras ou arrendá-las por parcos ganhos. Diante desse fato, surgem alguns questionamentos: quais foram às intervenções do órgão indigenista responsável pela garantia e direito dos indígenas no Brasil? Quais as intervenções do Estado para solucionar essa problemática? Qual foi a participação dos poderes municipais em denunciar essa realidade?

De acordo com os relatos de alguns indígenas o apoio municipal na aldeia é restrito: "À prefeitura de Rubiataba não nos ajuda em quase nada, mas quando chegam eleições existe uma disputa no voto dos índios entre representantes de Rubiataba e Nova América".

O descaso dos órgãos competentes só ratifica como os povos indígenas são tratados com esquecimento e descaso no Brasil. Os Tapuia representam mais um retrato dessa situação. Em todas as entrevistas realizadas, apenas uma conquista foi ressalta pelo atual cacique da aldeia - à escola indígena, criada em 2003, como mostra a figura 04: 


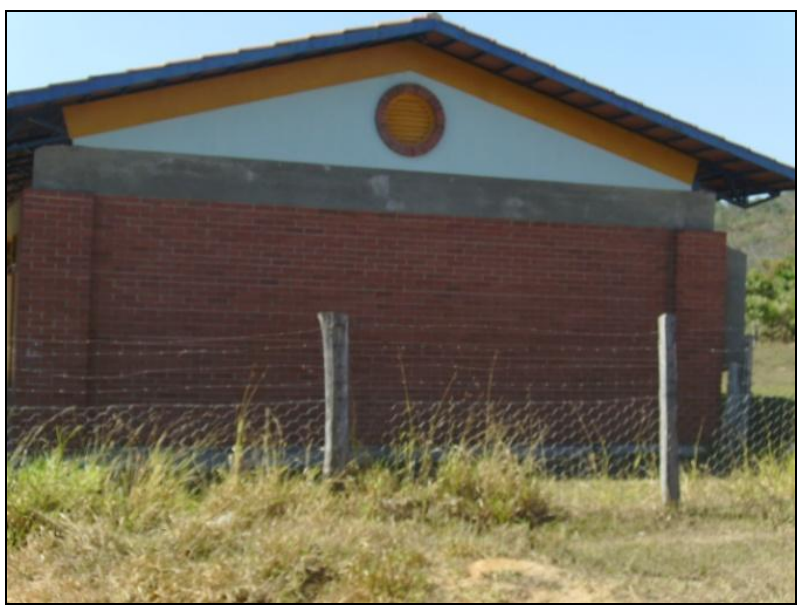

Figura 04: Escola indígena Tapuia

Fonte: fotografia da autora (2010)

O objetivo da escola é trabalhar a interação dos conhecimentos indígenas e não indígenas. Os educadores da escola e todos os estudantes são Tapuia. Retroalimentando-se da seiva da escola, dentro dela descobrem que é por ela é que vão inserir com a autonomia no mundo atual.

Atualmente, professores (as) indígenas, concluíram e ou fazem o Curso de Educação Intercultural de Formação de Professores Indígenas, na Universidade Federal de Goiás. Um dos eixos de destaque do curso é a diversidade e a sustentabilidade e tem como proposta pedagógica a interculturalidade e a transdisciplinaridade. Sobre a escola indígena argumentou uma das professoras:

"Ter uma escola indigena facilitou muito para todos além de ser uma grande conquista nossa. Apesar das dificuldades de aprendizagem os alunos são esforçados. É muito importante sempre resgatar nossa cultura na sala de aula. Os professores trabalham juntos para sempre o melhor".

A escola é um grande momento de rememorar e (re) criar a cultura indígena; ela proporciona trocas de conhecimentos valorizando os saberes de todos. O curso de Formação é apontado como um facilitador da aprendizagem, pois o corpo docente ganha caminhos teóricos e práticos para se pensar nas particularidades indígenas deste povo. Vê-se que a educação indígena ganha um sentido político crucial: é por ela que os povos Tapuia pode se reconhecer, valer-se de sua história, aceitar-se e, especialmente, desenvolver estratégias de enfrentamentos econômicos, políticos e culturais. 
A ressignificação da cultura do povo Tapuia é viva e demanda ações organizadas. A identidade é viva e precisa ser lembrada. O modo de vida tem vida e necessita de ser alimentado. Cada sujeito indígena é uma vida além de órgãos, nome ou outro atributo orgânico, compõe o estuário da cultura de um território e a história do país.

Por isso, é que o cacique tem nítida consciência quando revela que "a luta dos povos indígenas é pela vida, o grande desafio é a manutenção da vida.". E tal fato nos coloca outro questionamento: quais são os projetos e perspectivas dos Tapuia para sua comunidade?

\section{As Políticas Públicas e a Proteção da Biodiversidade}

Quando o bordão - a questão indígena é política e convoca a todos os segmentos para dela participar - é lançado e repetido, ele merece uma atenção crítica: a quem o Estado brasileiro nas últimas décadas tem subsidiado? Quem tem sido beneficiado com o processo vertiginoso de modernização do território e da agricultura?

Sem atacar diretamente estas indagações, pode-se assegurar que as Políticas Públicas têm se constituído nas principais ações de transformação dos Territórios Indígenas. Elas ao determinarem as áreas de confinamento e sua dimensão; os recursos disponíveis para a implantação de projetos de desenvolvimento, de melhoria da qualidade de vida no que concerne à saúde, ao saneamento básico, a educação, a comercialização artesanal, dentre outros, montam o índice de preocupação real do Estado para com esse segmento primaz e primordial da cultura brasileira: os povos indígenas.

Elas também constituem um dos mais importantes motores de transformação dos modos de relação entre indígenas e seus territórios. São elas que facilitam a liberação do território para exploração e ou pela simples deficiência em fiscalizar a exploração desordenada.

Desta maneira, as ações do Estado por intermédio das Políticas Públicas podem mobilizar transformar, ou inibir a relação dos povos indígenas com seus territórios. Para Bucci (2002, p. 204):

Políticas públicas são programas de ação governamental visando coordenar os meios à disposição do Estado e as atividades privadas para a realização de objetivos socialmente relevantes e politicamente determinados. Políticas públicas são "metas coletivas conscientes" e, como tais, um problema de direito público, em sentido lato. 
Ao considerar o modo de vida dos povos indígenas, a abordagem dessa temática deve ser cautelosa, especialmente pelo fato de que não se pode pensar a função do Estado destituída de interesses de classe, pactos políticos, ingerência geopolítica etc. Todavia, ela é crucial na criação, aprovação e implantação de políticas públicas voltadas a qualquer segmento social.

Em se tratando dos povos indígenas, quesitos como a diversidade cultural, assistência social, subvenção de projetos culturais, infraestrutura escolar, de moradia etc, não são apenas componentes técnicos. Como se vê, o dinheiro e o lume das políticas públicas são disputadas por governos das unidades federativas, setores da indústria, do ramo financeiro ou de outras ordens.

Quando as Políticas Públicas são vertidas em direção aos territórios indígenas, outro risco pode ocorrer: podem modelar as práticas culturais das diversas etnias de forma homogênea, não respeitando a multiplicidade de identidades culturais, tanto no plano individual quanto coletivo.

Ao colocar a questão dessa maneira, está evidenciado que o sentido universal da lei ou da política público pode desfazer das diferenças culturais e territoriais de cada povo. O contrário é saber que cada povo possui, de acordo com o seu território, um lugar nos lugares do mundo.

Isso posto, fica expresso que os estudos da política pública de cada povo indígena exige uma leitura de acordo com cada território e suas necessidades. Se o vetor central que explica o conteúdo sociocultural de um povo indígena é a diferença cultural, é preciso construir Políticas Públicas diferenciadas para cada povo.

Ao contemplar a heterogeneidade e a independência de cada povo também é necessário capacitar os índios a atuarem junto às estruturas públicas e privadas em prol dos seus direitos e interesses. Aqui entra o que se tem denominado arco de poder. As diferentes instituições que fazem parte de um município ou de uma unidade federativa são chamadas a se posicionar sobre a causa indígena.

No caso do povo Tapuia, as Políticas Públicas, com ação de diversos segmentos, foram importantes na execução de projetos como a Escola Indígena, a criação de gado, a lavoura comunitária, a fábrica de mandioca ${ }^{6}$, a

${ }^{6}$ O Projeto da Fábrica de Mandioca é realizado em parceria com o Conselho Indigenista Missionário- CIMI, a produção da farinha é para todas as famílias envolvidas no projeto que é desenvolvido pelas mulheres da aldeia, com objetivo de promover uma interação entre elas e a sustentabilidade da comunidade. Para o cacique esta ação visa "na verdade" tirar as mulheres do anonimato. 
criação da Associação dos Índios Tapuia do Carretão - AITCAR, com reuniões freqüentes na sede da comunidade.

Deve-se destacar, todavia, que de acordo com a reflexão que tem sido feita, as Políticas Públicas não garantem, por si só, a soberania desse povo. Os conflitos pela terra existem cotidianamente, às vezes silenciosamente, outras vezes com maiores ímpetos. Observa-se que a terra é, para os povos indígenas, além de componentes da sobrevivência uma seiva cultural, onde os hábitos e os costumes podem ser mantidos e utilizados na comunicação vital entre os pares.

Mais da metade da população Tapuia encontra-se desaldeada atualmente. Um dos motivos segundo o cacique é a pequena dimensão da terra que não garante o sustento de todas as famílias Tapuia. Muitos sujeitos indígenas, apesar de morarem na aldeia, trabalham fora, geralmente em Rubiataba, Nova América e nas fazendas próximas. São atividades diversas desde diarista, até vaqueiros, dentre outras. A ausência de terra própria consiste na permanência da subordinação.

Além da sobrevivência, do componente cultural, a terra, especialmente por se situar no Bioma Cerrado, possui outro aspecto que, embora não sejam separados dois anteriores, possui uma dimensão própria: a biodiversidade. Ou seja, é da rica tradição indígena de Goiás, a ligação de sua vida com os elementos da natureza.

E é especialmente relevante o papel do conhecimento que os povos indígenas possuem das espécies, dando a elas sentido variados, desde os mitológicos, incluindo o uso de espécies da flora ou da fauna para colocar nomes nos filhos, até o uso diário. Os saberes indígenas se estendem para uma rica variação de funções. O cacique dos Tapuia, em campo, revelou que ele e seu povo conhece mais de 160 espécies que usam para medicina popular, alimentação, instrumento de trabalho etc.

Em face a importância do Cerrado para os povos Tapuia, paradoxalmente, não existe, na atualidade, nenhum projeto e nem políticas que visam a proteção da biodiversidade do território Tapuia. Cada porção de seu território que hoje se encontra como propriedade privada de algum fazendeiro representa perdas de seus ambientes naturais importantíssimos à vida indígena e suas práticas culturais. Sobre a utilização e conhecimento das plantas do Cerrado, uma das entrevistadas disse que:

"São os mais velhos que identificam as plantas e fazem as garrafadas para o nosso próprio consumo. Encontramos na reserva: rabo de tatu; sucupira; cabeça de nego; buchinha; velame branco; barbatimão, e tantas outras, tem planta que mata, é melhor acreditar somente em quem conhece elas". 
Fica evidente que mesmo depois de séculos, quando a ciência compreendeu o valor do conhecimento indígena sobre a flora e a fauna não existe políticas públicas e ou outra ação do Estado que garantem aos povos indígenas uma quantidade de terra mínima para sobrevivência e manutenção dos recursos naturais de acordo com os seus saberes e suas necessidades.

Ao contrário, corre um debate entre os Movimentos sociais no Brasil que é levado aos grandes fóruns políticos que vêem a exploração dos conhecimentos indígenas por multinacionais de medicamentos e laboratórios genéticos, com a conivência das políticas neoliberais e das privatizações efetivadas pelo Estado brasileiro.

O confinamento do território dos povos Tapuia em meio a fazendeiros que, no passado, grilaram as suas terras, significa uma obliteração na preservação da biodiversidade. Significa também uma pressão para que saiam de seu território em busca de outras fontes de sobrevivência por meio do trabalho subordinado.

\section{Considerações Finais}

A partir das reflexões apontadas no presente artigo, foi possível averiguar que o povo Tapuia, apesar de anos de lutas, ainda não tem à garantia da ampliação da demarcação de suas terras. Isso interfere em sua permanência em seus territórios, bem como fratura as possibilidades de que tenha autonomia na produção de sua vida.

Tal fato é um problema que provoca entrave em vários aspectos do seu modo de sua vida, sobretudo na realização de suas práticas culturais, bem como a permanência de todas as famílias Tapuia em seu território.

A enorme quantidade de sujeitos indígenas desaldeados impõe uma cisão interna entre parentes que ficam e que saem. Essa questão, também, interfere nos conflitos identitários que se reacendem ao longo dos anos, inclusive como apanágio ideológico dos fazendeiros que apregoam "que aquele povo não é índio".

A escola indígena uma das principais conquistas desse povo, mostra que não se pode esperar das políticas públicas que estão na grande maioria vinculadas ao Estado que sofre pressões das diferentes forças que constroem o cenário econômico no Cerrado. Desde modo, para o povo Tapuia está sendo pela educação indígena que o autoconhecimento se ajusta na composição de sua autonomia. 
É importante salientar que a escola para os índios, durante muito tempo foi o lugar onde se desaprendia todo conhecimento que eles tinham sobre seu povo. Ao considerar a educação brasileira pode ser a escola indígena a única coisa nova. Mesmo ainda com interferências não indígenas, houve muitos avanços.

Ao refletir assim, está em questão como diferentes segmentos sociais organizados constroem o seu arco de poder e, embora com conteúdos culturais específicos, podem articular, organizar demandas, pressionar o Estado, desenvolver a sua condição de sujeito coletivo.

Um povo alegre e aberto ao Outro. Essa é a impressão que fica quando se aproxima dos Tapuia. São os relatos do futebol, do cultivo das hortas, das conquistas das lidas diárias com o gado e outras atividades. As brincadeiras e intermináveis rodas de conversa ao relento ainda fazem parte de suas vidas.

Portanto, os Tapuia, a todo o momento, têm que desenvolver estratégias e táticas para a constituição e afirmação de sua identidade étnica frente à sociedade não-indígena. Um código rígido interno de que não podem beber bebidas alcoólicas, fazer vandalismo e outros preceitos são uma vigilância necessária para a construção de sua consciência coletiva. E impor um respeito à comunidade externa.

Contudo, hoje em pleno século XXI, o que se vê na comunidade Tapuia é a marca de duas palavras que se imbricam: resistência e esperança. $\mathrm{O}$ povo Tapuia resiste às entranhas de um tempo histórico, pontuado de massacres e desrespeito com os povos indígenas e vão se tornando a cada desafio protagonistas de seus projetos de futuro.

\section{Referências}

BUCCI, Maria. Paula. Dallari. Políticas públicas: reflexões sobre o conceito jurídico. São Paulo, Ed: Saraiva, 2006.

CHAVEIRO, Eguimar Felício. Goiânia, uma metrópole em travessia. Tese. (Doutorado em Geografia Humana) - Departamento de Geografia, USP, São Paulo, 2001.

CHAVEIRO, Eguimar Felício. O Cerrado em Disputa: sentidos culturais e práticas sociais contemporâneas. In: Geografia e Cultura: os lugares da vida e a vida dos lugares. ALMEIDA, Maria Geralda de; CHAVEIRO, Eguimar Felício; BRAGA, Helaine Costa (orgs). Gráfica e Editora Vieira. pp. 75-97. Goiânia, 2008. 
ESTEVAM, Luís. O tempo da transformação. Estrutura e dinâmica da formação econômica de Goiás. Goiânia. Edição do autor, 1998.

FUNAI. Fundação Nacional do Índio. Fonte: http://www.funai.gov.br. Acesso em 10 de Agosto de 2013.

MENDONÇA, Marcelo. Rodrigues. A urdidura espacial do capital e do trabalho no Cerrado do Sudeste Goiano. Dissertação (Doutorado em Geografia) - Universidade Estadual Paulista Júlio de Mesquita Filho, UNESP. Presidente Prudente, 2004.

MOURA, Marlene Castro Ossami de. Aldeamento Carretão: "marco zero" da história das relações interétnicas dos tapuios. Revista Dimensões. Vol: 18. Ed: Programa de Pós-Graduação em História (PPGHIS) e do Núcleo de Pesquisa e Informação Histórica (NPIH) da Universidade Federal do Espírito Santo. Acessível em: http://www.ufes.br/ppghis/dimensoes. 2006.

PEDROSO, Dulce Madalena Rios. Avá-Canoeiro: A história do povo invisível Séculos XVIII e XIX. Dissertação de mestrado em História das Sociedades Agrárias. Goiânia: Instituto de Ciências Humanas e Letras/UFG, 1992.

RAVAGNANI, Oswaldo Martins. A experiência xavante com o mundo dos brancos. Araraquara: Unesp-Faculdade de Ciências e Letras, 1991. (Col. Textos n ${ }^{\circ}$ 9)

RIBEIRO, Darcy. Os índios e a civilização: Integração das populações indígenas no Brasil moderno. Rio de Janeiro: Civilização Brasileira, 1970.

SILVA, Cristhian Teófilo da. "Parados, bobos, murchos e tristes" ou "caçadores de onça"? Estudo sobre a situação histórica e a identificação étnica dos tapuios do Carretão/GO. Boletim Anual do Geri (Grupo de Estudos em Relações Interétnicas). $\mathrm{N}^{\circ}$ 04. Universidade de Brasília. Instituto de Ciências Sociais. Departamento de Antropologia. 2000.

TRINDADE, Israel Elias. O fenômeno da Monotongação no Português Tapuio. Dissertação de Mestrado do Programa de Pós-Graduação em Letras e Lingüística da Universidade Federal de Goiás. Banco de teses e dissertação da UFG. 2009. 


\section{Lorranne Gomes da Silva}

Graduada em Geografia pela Universidade Estadual de Goiás. Mestre em Geografia pela Universidade Federal de Goiás, onde atualmente é doutoranda.

Professora do curso de Geografia da Universidade Estadual de Goiás - Unidade Universitária de Quirinópolis.

Rua José Reinaldo Vieira, número 480, Centro - Caçu/Goiás, CEP: 75813-000 lorrannegomes@gmail.com

Recebido para publicação em dezembro de 2012 Aprovado para publicação em abril de 2013 